\title{
Analyzing client-led innovation enablers in Australian construction projects
}

\begin{abstract}
Purpose - This research examined how Australian construction projects perform in the area of client-led innovation. The purpose of the research was to test the influence of a set of enablers in promoting the innovative performance of construction projects and examine how Australian construction projects perform in relation to innovation.

Design/methodology/approach - A questionnaire was developed distributed to over 300 construction industry practitioners to obtain perceptions of industry practitioners regarding client-led enablers to promoting innovation at the project level, with 131 valid responses received. The data from the survey was subjected to statistical analyses including mean comparisons, using the Mann-Whitney U Test and Kruskal Wallis Test.
\end{abstract}

Findings - This research identified a number of enablers that clients can employ in construction projects to enhance innovative performance. It also revealed that the innovative performance of construction projects in Australia appears to be above average, although the perceived level is not too high. The main finding of the research is that Australian clients could achieve higher outcomes from construction projects by promoting innovativeness in their projects, especially by promoting innovativeness in their own organizations and providing incentives/ rewards and other support for innovative activities in projects.

Originality/value - Past research focusing on client-led enablers at the project level is limited. This research identified a number of enablers that clients can employ to achieve greater benefits from their projects through innovation.

Key words construction industry, client, creativity, enablers, incentives, innovation, project level

Paper type Research paper

\section{Introduction}

Innovation is the tool used by humankind to achieve great strides in almost all spheres of life. In any dynamic economy, innovation is the catalyst for its development and growth (Murphy et al., 2011). Innovation can drive productivity improvement across all industrial sectors (Gans and Stern, 2003). Construction industry has also benefited from innovation as reported by numerous researchers. These benefits include: decreased cost, competitive advantage, higher quality and increased productivity (Gambatese and Hallowell, 2011); increased organizational commitment and higher organizational motivation (Dulaimi et al., 2003; Lu and Sexton, 2006); organizational effectiveness (Dulaimi et al., 2005); and additional cost savings in future projects due to gained experience, health and safety improvements, minimized waste, reduced carbon emissions, enhanced corporate image and recognition, future collaboration along the supply chain, knowledge transfer to inform future projects, client and end user satisfaction, and improved quality of life for local people (Ozorhon, 2013). Therefore, innovation is highly beneficial to the construction industry. In 
order to achieve these benefits, it is necessary to initiate and sustain innovative activities in a construction project.

Although there are many players, the client is considered to have the significant capacity to exert influence and foster innovation in a construction project. According to Ozorhon (2013), clients play an important role in both creating the project conditions in which innovation can flourish and in understanding and communicating end user needs to the project team. Many researchers such as Blayse and Manley (2003), Briscoe et al. (2004), Kulatunga et al. (2011), Manley and Mcfallan (2006) and Nam and Tatum (1997) highlighted the important position of a client in a construction project and the role that a client can play in promoting innovation. According to Asad et al. (2005), clients can act as a catalyst to foster innovation by exerting pressure on the supply chain partners to improve overall performance and by helping them to devise strategies to cope with unforeseen changes, by demanding high standard of work, and by identifying specific novel requirements for a project. Blayse and Manley (2003) stated that the more demanding, experienced and technically competent the client, the more likely it is to stimulate innovation in projects commissioned. Actions to promote innovation in construction can be initiated by many such as the construction industry or by governments. In her study on implementation of innovation by manufacturers subcontracting to construction projects, Manley (2008) discussed the role of the construction industry and the regulations by governments to promote innovation in construction projects. However, the actions taken by clients are the easiest to implement as such actions do not need external help. This research is on such client-led actions or enablers to promote innovation in construction projects.

Even though the clients are motivated to facilitate innovation in construction projects, currently there is insufficient knowledge as to what actions need to be taken as explained later in the paper. This research places an emphasis on the enablers that clients can use in a construction project, either directly or through the project team, to generate and foster innovative activities.

\section{Rationale for the Current Study}

It is apparent that enablers to stimulate innovation in construction projects have not been widely researched as the emphasis has mostly been on organizational innovation. There have been relatively few studies on the performance of innovation in the Australian construction industry. Manley $(2006,2008)$ looked at the innovation competence of public sector construction clients and implementation of innovation by manufacturers subcontracting to construction projects. Manley and Mcfallan (2006) also explored the drivers of firm-level innovation in the construction industry. Panuwatwanich (2008) examined the innovation diffusion process in Australian architectural and engineering design organizations. However, most of these studies were on the construction industry as a whole and organizations working in the industry in particular. The broader literature review undertaken in support of this research did not find studies carried out comprehensively on enablers that promote innovation at the project level.

It is apparent that much less attention has been given to project level innovation. Project level innovation focuses on innovation related actions undertaken by project personnel during the execution of the project (from the inception to construction and handover phases). The project personnel could include the client's team, designers, contractors and suppliers (both service suppliers and material and equipment suppliers) and the management team of the client organization. Citing other researchers, Ozorhon (2012, p. 455) commented that "much of construction innovation is codeveloped at the project level. However, most of the literature has focused on investigating innovation at the firm level, and the project level has 
largely been ignored. This is primarily because of the difficulties in monitoring the different activities conducted by different parties in each stage of a construction project. Chen (2014) added that despite the panoply of studies that use a wide variety of measures to describe innovation outcomes and the input characteristics that affect those outcomes as well as firm performance, most studies focus on firms engaged in innovation and relatively few studies explore projects engaged in innovation. Brockmann et al. (2016) also supported this argument by stating that we are lacking knowledge on the details of innovation in construction projects.

Innovation enablers at the project level have been included in other studies. However, not many of these enablers are under the control of clients. For example Manley (2008) identified some regulatory conditions that promote innovation outcomes. Implementation of regulations is, however, outside the control of clients. If enablers that can be implemented by clients are investigated, such knowledge would be of much practical significance as clients can use with ease. The client-led enablers considered in this research do not depend on external conditions, such as market conditions and government intervention, for implementation. Therefore, they are more likely to be implemented directly by clients interested in enhancing project outcomes through innovation.

This research provides an opportunity to achieve a broader understanding of the innovative performance of the Australian construction industry and to investigate into matters affecting the innovative performance of construction projects. It attempts to find answers to the following questions:

- What are the enablers that construction clients can use to promote innovation in construction projects?

- How do these enablers perform with respect to innovation?

- How innovative are Australian construction client organizations?

- Are there any factors that might be associated with project level innovations?

Before finding answers to above questions, it is necessary to understand the background leading to the research.

\section{Conceptual Background}

The literature review identified a large number of enablers that promote innovation in workplace situations. These enablers can be grouped under the following categories: (1) Idea harnessing (strategies that can be used for the generation of new and beneficial ideas and implementing them) ; (2) Relationship enhancement (actions that can be used to improve relationship between parties engaged in the project); (3) Incentivisation (the types of incentives/ rewards that can be provided to promote innovative activities); and (4) Project team fitness (deliberate actions that can be taken to strengthen the project team and improve its capability to focus on innovative activities). They are described in detail below.

\subsection{Idea harnessing}

As mentioned earlier, innovation is the successful implementation of novel ideas (Shalley et al., 2004). Innovation is more likely to be conceived in a project setting where all members are willing to create new ideas and implement these to find solutions to the problems (Ozorhon and Oral, 2017). Idea harnessing is concerned with taking appropriate actions to acquire beneficial ideas and implementing them. Ideas can come from many sources. Bygballe and Ingemansson, (2014) identified co-workers, customers and personal networks 
(which are likely to include co-workers) as most important sources of innovation in construction projects.

There are techniques and strategies available that could be used in projects to harness beneficial ideas. The techniques include the use of the suggestion box (or web-based idea acquiring systems) and brainstorming. In addition, Panuwatwanich (2008) identified scenario planning, risk assessment planning, life cycle costing, value engineering and value management as idea harnessing techniques.

Several other idea harnessing strategies also include such techniques as seeking ideas from external personnel who are not directly involved with the project and getting inputs from experienced personnel, key stakeholders, contractors and suppliers and fellow staff and workers. According to Núñez (2011), it has been shown that more new ideas are generated when people are exposed to others who do not belong to their cohesive group.

Furthermore, those organizations that want to foster innovation should provide an environment where people from different backgrounds and experiences can interact and build on others' knowledge (Núñez, 2011). Engaging suppliers earlier on in the process as an idea harnessing strategy was recommended by Rahman and Alhassan (2012), Ozorhon et.al. (2016) and Tatum (1989). Capturing project learnings, often referred to as "postmortem analysis", is another strategy. This is a structured ritual according to Schieg (2007), conducted at the end of a project to identify strengths and weaknesses in the project operation. Post-mortem analysis is an effective knowledge sharing strategy. According to Ozorhon et.al. (2016), knowledge sharing is essential not only in bringing the right ideas into the project, but also in ensuring that these ideas are communicated to the entire project team and diffused to future projects. Idea harnessing is to make use of techniques and strategies, such as those mentioned above, to identify relevant innovations.

\subsection{Relationship enhancement}

Relationship enhancement is the next category vital for stimulating innovation. According to Ling (2003), no innovation could be achieved in an adversarial environment. Although it might be arguable that innovations may emerge in some adversarial environments due to competitions, Ling's research was conducted in the context of construction industry in which the environment was referred to as the immediate environment between the players involved with generating and implementing innovations.

Relationship enhancement is employing actions to improve relationships within the project team and between parties to the project such as contractors, consultants, service providers and suppliers. Researchers have identified the importance of improved relationship between parties for the promotion of innovation. For example, Asad et. al. (2005) concluded that contractor-client cooperation can act as a catalyst to promote innovative thinking and collaborative culture. Ozorhon et. al. (2016) also identified cooperation as an innovation enabler and stated that successful innovation requires effective cooperation, coordination, and integration among contractors, subcontractors, suppliers, architects, engineers, and clients in construction projects.

There are many ways of strengthening the relationship between parties. The concept of 'relationship contracting' is a way to enhance relationship between parties. According to Cheung and Rowlinson (2011), relationship contracting embraces and underpins various approaches, such as partnering, alliancing, joint venturing, and other collaborative working arrangements and equitable risk sharing mechanisms. Davis and Love (2011) stated that the relationship development process represents a major contributor to successful alliance contracting and can add considerable value throughout the supply chain. 


\subsection{Incentivisation}

Research shows that innovative activities in a project could be enhanced by encouraging and providing incentives or rewards to augment synergistic motivation of those engaged in the project. According to Price (2002), rewards encourage team members to work harder and compete more effectively since they directly benefit from their efforts. Rewards also expose the organization's priorities and show its commitment. Dulaimi et al. (2002) and Price (2002) found that successful innovation may come about if companies establish a reward system to recognize innovators and to promote innovation. Ozorhon et.al. (2016) also highlighted the importance of rewards in promoting innovation in construction projects.

Alliance is a delivery type that promotes incentivisation. Alliancing can be identified as having specific relationship elements (e.g. trust, leadership and commitment) established among partners as a driver for collaborative behaviors and identity, hence strengthening the sources towards innovation (Ibrahim et al., 2017). A major component of alliance framework is the use of risk/ reward model to encourage project team members to work together in a cooperative and integrated way so that rewards match performance. After studying the incentive aspects of this risk/ reward model, Love et al. (2010) found that the model led to a positive and constructive behaviors occurring due to their perceived fairness and equity of payment structure.

\subsection{Project team fitness}

All the strategies mentioned above may not work unless the client's team is capable and focused on enhancing innovation. Supporting this conclusion, Khalfan and McDermott (2006) stated that "it is generally accepted that, implementing innovative processes, whether related to new product development or enhanced project delivery, may result in failure of all the hard work without any motivation and efforts from the people actually responsible to carry out those processes". Ibrahim et al. (2017) added stating that one of the most important factors driving the innovation is the presence of a well-integrated team exhibiting collaborative behavior. Therefore, the client's team should be highly motivated, experienced and knowledgeable on promoting innovation within the project. By combining knowledge, skills, and abilities of individuals with different perspectives and backgrounds, teams provide ideal conditions for stimulating creativity and innovation via social and psychological processes. As a result, focusing on teams and creating the necessary condition for them is one means by which innovation can be fostered in organizations (Panuwatwanich et al., 2008). Project team fitness encompasses the strategies that can be undertaken to strengthen the capabilities of the project team, enabling them to focus on innovative outcomes.

One of the most important strategies in strengthening the client's project team is to hire a capable project manager. From their study on client's championing characteristics that promote construction innovation, Kulatunga et al. (2011) found that the following characteristics promote innovation in construction projects:

- Client's foresight and vision;

- Demand for innovation;

- Client's support to innovation;

- Client needs to be an effective team player;

- Client needs to develop mutual trust and understanding between individuals;

- Client's respect for people is vital;

- Client's professional competence;

- Ability for effective dissemination of information;

- Client's value judgment; 
- Ability to maintain strong relationships between project members and other external stakeholders;

- Ability to maintain up-to-date knowledge about project development;

- Flexible and receptive to change;

- Establishing reasonably firm goals and priorities; and

- Ability to manage risk.

The client is represented by the project manager at the construction project. Therefore, it is vital for the client to appoint a project manager with the above values to lead the project.

According to Cheng et al. (2005), highly effective project managers (whom they call superior managers), demonstrate a higher level of:

- Achievement orientation - showing improvement in performance, more entrepreneurial behavior and more innovative ideas for new services;

- Initiative - proactive actions to avert problems in order to enhance job results;

- Information seeking - proactive exploration of issues and solutions outside their immediate environment;

- Focus on client's needs - effort to meet their client's requirements;

- Impact and influence - proficiency in coordinating, inspiring and directing the team;

- Directiveness - effort to ensure that individual subordinates comply with his/her wishes in the way that was intended;

- Teamwork and cooperation - influencing the team to perform in a desirable manner;

- Team leadership - recognizing when and when not to act authoritatively if they are to get the best out of their colleagues;

- Analytical thinking - conception, analysis and reasoning in order to make appropriate management decisions;

- Conceptual thinking - being able to see the bigger picture;

- Self-control - staying calm and maintaining performance under stressful conditions; and

- Flexibility - remaining adaptable and flexible to solve the problems in hand.

For innovation to thrive, there needs to be a conducive environment. Panuwatwanich, et al. (2008) emphasized the important role of providing a conducive environment by the organization in the successful management and diffusion of innovation. They stated that even though an organization decided to adopt a particular innovation, such innovation is not likely to be fully utilized if the employees perceive no encouragement and support from the firm. It is easy to establish a strong supportive environment if the client organization, itself, is innovative. Such innovative organizations have the culture and climate conducive to innovation (Panuwatwanich et al., 2008). Therefore, clients interested in achieving enhanced benefits through innovation first need to establish the culture and climate conducive to innovation in their own organizations.

The literature review to derive the above groups of enablers came from research on both constructions projects as well as from other workplace situations. As construction is another workplace activity, these enablers were tested in construction situations in this research.

The following section discusses how the research was conducted, using the conceptual background. 


\section{Methodology}

The main questions driving the research discussed in this paper were: how innovative are Australian construction projects as perceived by project personnel and how do the client-led enablers perform at the project level to promote innovation in these projects?

A questionnaire was developed based on important enablers that clients could use to promote innovation while managing construction projects. This was done through a comprehensive review of literature, with questionnaire items adopted from previous similar research. The survey participants were project team members working for the client (or owner) of the project. They were from a team representing the owner such as the consultant, design and superintendent team. The developed questionnaire was then pretested with ten highly experienced industry practitioners, which included face-to-face interviews to seek feedback on the face validity of the questionnaire. The questionnaire was revised and refined based on the feedback received.

\subsection{The questionnaire}

The questionnaire consisted of three parts: (1) project information; (2) client-led enablers under different categories and innovative performance of the project; and (3) background information about the participants and their organizations.

Project information (Part 1) requested general details of the project, such as main engineering area, delivery type, cost and complexity.

The questions related to client-led enablers (Part 2) were under the following categories: idea harnessing (Group A), relationship enhancing (Group B), incentivisation (Group C) and project team fitness (Group D). This section also included the participant's perception of the project's innovative performance (Group E). Altogether, Part 2 of the questionnaire had 63 questions. Table 1 shows the areas covered under each category and the example questions included under the category.

\section{[Insert Table 1 here]}

The last section (Part 3) consisted of questions related to background of participants and their organizations such as gender, level of education, age group, professional experience, main engineering area of the organization, occupation and type of the organization.

\subsection{The survey}

The questionnaire was distributed to over 300 construction industry practitioners by post and through emails. They were identified through an online search using key words such as local government institutions, city councils, road authorities and included all engineering statutory bodies at federal, state and local government levels (e.g. all road authorities, city councils), construction companies and other engineering service suppliers such as consultants, designers and geotechnical service providers. In total, 131 valid responses were received, representing about $44 \%$ effective response rate. Given below is an assessment of this response rate.

As pointed out by Bhattacherjee (2012) survey research is generally notorious for its low response rates. A response rate of $15-20 \%$ is typical in a mail survey, even after two or three reminders (Bhattacherjee 2012). Sills and Song (2002) reported of response rates varying from $70 \%$ to $0 \%$ for internet surveys.

This response rate is better than some of the surveys conducted in the area of construction. For example, Manley (2006) conducted a survey to assess the innovation competence of repeat public sector clients in the Australian construction industry, with a distribution of 1,371 
questionnaires and receiving a response rate of 29\%. Panuwatwanich (2008) also conducted a survey to model the innovation diffusion process in Australian architectural and engineering organisations and had a response rate of $34.81 \%$, while Hughes and Thorpe (2014) had a response rate of $40.4 \%$, with a survey to review enabling factors in construction productivity in Australia. Therefore, the response rate of the survey is considered adequate for this type of research.

\subsection{Data Screening}

Data screening was undertaken to examine the fundamental characteristics of the dataset to ensure that it was suitable for the statistical techniques employed in the subsequent analytical stages. This included missing data analysis, assessment of normality, outliers screening and assessment of standard deviations and standard errors of the mean. After undertaking these data screening procedures, the sample size was reduced to 115 . Those eliminated included the responses with significant missing data and those that were identified as outliers. Note that the reduced sample size of 115 can be equated to the reduced response rate of $38.33 \%$ (from $44 \%$ ), which is still considered an acceptable response rate.

In statistical data analysis, standard deviation (SD) is a measure of how a set of data is clustered or distributed around its mean. The more spread out or dispersed the data, the standard deviation is large. On the other hand, the more concentrated or homogeneous the data is, the standard deviation is small (Berenson et al., 2006). Therefore, a large SD indicates that the scores cluster more widely around the mean, thus the mean is not a good representation of the data. A small SD, on the other hand, indicates less dispersed data points about the mean, thus adequately represents the data. The coefficient of variation (CV) can be used to assess whether SD is high or low. Coefficient of variation is defined as Standard Deviation divided by Mean. As a rule of thumb, CV>1 indicates a relatively high variation, while $C V<1$ can be considered as low (Stine and Foster, 2011).

Analyzing the variables used in the study, it was found that the CV values changed from 0.13 to 0.38 . This indicates that all variables have comparatively low values of standard deviation. Therefore, it can be assumed that the data is spreading closer to the mean and the mean can be used to interpret the data.

\subsection{Statistical analysis}

The statistical analysis was further conducted on the five independent scales representing four client-led enablers (i.e. idea harnessing, relationship enhancement, incentivisation, project team fitness) and innovative performance. To ensure that such a set of measurement scales consistently and accurately captured the meaning of the identified factors, an analysis of scale reliability was performed through an assessment of internal consistency and item-total correlations. The analysis was carried out using SPSS Version 24. Cronbach's alpha coefficient was calculated to assess the degree to which responses are consistent across the items (variables) within a single measurement scale. As a guideline, Kline (2005) suggests that an alpha coefficient around 0.90 is excellent, around 0.80 is very good, and around 0.70 is adequate. All the Cronbach's alpha coefficients calculated for the five independent scales were more than 0.70 .

An item-total correlation test was performed to check if any item in the set of tests is inconsistent with the averaged behavior of the others, and thus can be discarded. According to Pallant (2005), a value of the corrected item-total correlation of less than 0.30 indicates that the variable is measuring something different from the construct as a whole. There 
were no values of the corrected item-total correlation of less than 0.30 indicating that all the variables were measuring relevant constructs.

Having prepared the data after screening and testing for scale reliability, a statistical examination was conducted to derive information to assess the performance of five independent categories (i.e. four client-led enablers and project innovative performance) and individual variables with respect to their influence on project innovation. In particular, high and low performing variables were analyzed. This examination was also extended to compare the performance between internal groups such as projects undertaken by public and private sector organizations, different delivery types and cost types. The statistical findings were explained in practical terms, where possible.

\section{Results}

\subsection{Preliminary Analysis}

\subsubsection{Respondent profile and project information}

Most of the survey respondents were male (89\%). They were mostly from the 56-65 years age group ( $41 \%)$ followed by $46-55$ years age group (26\%). Most of them preferred to be designated as engineers (63\%) followed by those preferred to be called as project managers $(26 \%)$.

Most of the projects for which the details were provided, were from the roads and bridges sector $(46 \%)$ followed by public utilities $(15 \%)$ and mining, oil and gas $(11 \%)$. Others included the construction of large buildings $(6 \%)$, water resources $(6 \%)$, railways $(4 \%)$ and power and electrical (3\%).

With regard to the cost of the projects, the majority $(56 \%)$ belonged to the range from $\$ 1$ Million to $\$ 100$ Million, followed by the range from $\$ 100,000$ to $\$ 1$ Million (17\%) and over $\$ 200$ Million (14\%). There were only $7 \%$ with a cost less than $\$ 100,000$. Similarly, there were $7 \%$ with a cost between $\$ 100$ Million to $\$ 200$ Million.

The survey also collected information on project delivery types. With $50 \%$ of all projects being design and build, this was the mostly used delivery type, followed by design, bid and build (34\%). While $4 \%$ belonged to Early Contractor Involvement delivery, the rest $(13 \%)$ belonged to Alliance or other collaborative contracts.

In addition, the survey collected information on the use of idea generation techniques and the form of relationship of the client's team with the contractor. They are discussed below.

\subsubsection{Use of idea generation techniques}

In the survey, the respondents were requested to provide information on the types of idea generation techniques used in their projects. Some of the idea generation techniques identified are explained below:

- Brainstorming: process for generating creative ideas and solutions through intensive and freewheeling group discussion with ideas spontaneously contributed by its members.

- Online idea database: web-based system for people to contribute and record their ideas, generally on a specific topic.

- Scenario planning: process of visualizing what future conditions or events are probable, what their consequences or effects would be like, and how to respond to, or benefit from, them. 
- Risk assessment planning: process of evaluating risks, estimate impacts, and define responses.

- Constructability review: This is the review exploring the extent to which a design is facilitating the efficient use of construction resources and enhancing the ease and safety of construction on site whilst meeting the client's requirements.

- Life cycle costing: process of determining the most lifetime cost-effective option among different competing alternatives, when each is equally appropriate to be implemented on technical grounds.

- Sustainable design: The consideration of issues related to sustainability such as energy efficiency, water efficiency, the indoor environment, site locations, material usage and atmospheric consideration in the design.

- Value management: A strategy of examining every aspect of the whole project to ensure that all of the expectations can be delivered in a most economical way.

- Value engineering: A systematic approach for enhancing value by eliminating unnecessary costs while maintaining function.

Table 2 provides information on the use of idea generation techniques as reported by the survey respondents.

\section{[Insert Table 2 here]}

It can be seen from the above results that scenario planning is the most widely used idea generation technique practiced in Australian construction contracts while constructability review, sustainable design, value management or value engineering were least utilized. Most of the projects reported in the survey were from $\$ 100,000$ to $\$ 100$ Million range where scenario planning is used both for contingency planning and risk management planning. This may be the reason for the high percentage of scenario planning as an idea generation technique. On the other hand, constructability review, sustainable design, value management or value engineering would mostly be used for very large (over $\$ 100$ Million) and complex projects, therefore not much used.

\subsubsection{Form of relationship with the contractor}

Different types of relationships were identified in the survey and the respondents were requested to identify the types relevant to their projects. They are explained below.

- Traditional: The traditional or the conventional approach to projects involves discrete design development, tender and contract award and construction delivery phases (i.e. design, bid and build).

- Partnering: Parties voluntarily agree to co-operate in a partnering relationship without any legal effect.

- Extended Partnering: This is a formal process. Although not legally binding, the partnering process may be included in the tender documents as an option. Usually, this includes a series of meetings, workshops and reviews.

- Collaborative: relationship based on legally binding agreement to work cooperatively, on the basis of sharing project risk and reward, for the purpose of achieving agreed outcomes based on principles of good faith and trust and an open book approach towards costs.

The analysis of the results on the form of relationship with the contractor is given in Table 3 .

\section{[Insert Table 3 here]}


According to this table, traditional, but collaboration taken seriously means a relationship without any formal agreements such as partnering entered into with parties. However, the parties recognize that the collaboration is important for effective execution of the project.

It can be seen from Table 3 that most clients resort to the traditional, but collaboration taken seriously form of relationship. Partnering is also popular up to some extent but extended partnering and collaborative contracting were least utilized.

Having discussed the details of survey participants and their projects, the following section provides information on the statistical analysis used and the results from the analysis.

\subsection{Main Findings}

\subsubsection{Measurement scale}

The survey was based on innovative attributes of client's project teams engaged in construction projects in Australia. The survey respondents were given the choice to answer whether they strongly disagree, disagree, neutral, agree and strongly agree to the positive innovative attributes. These were ranked from 1 to 5 , indicating 1 is worst performer (strongly disagree) and 5 is the best performer (strongly agree). As 3 was the median value representing the neutral position, therefore, the cut-off value from good performance and bad performance, the following scale was used to interpret the results.

- Mean value <2: extremely unsatisfactory performance

- Mean value 2-3: unsatisfactory performance

- Mean value 3-4: satisfactory performance

- Mean value $>4$ : extremely satisfactory performance

Based on the above scale, the statistical analysis undertaken identified valuable findings, which are presented below for: the overall client-led enablers and project's innovative performance scales, followed by the findings regarding the performance at the variable level.

\subsubsection{Client-led enablers and project's innovative performance scales}

The four scales of client-led enablers (Groups A to D) in Table 1 and the project's innovative performance scale (Group E), derived using the literature review were statistically analyzed to determine their performance. The results are presented in Table 4.

\section{[Insert Table 4 here]}

According to the table, the project innovative performance scored a relatively high value of 3.63. This indicates that Australian construction projects perform satisfactorily in the area of client-led innovation. The table also shows that among the four categories, incentivisation has the lowest mean of 3.08. It appears that the Australian clients are less inclined to provide rewards/ incentives to improve performance. All the other categories have mean values between 3.5 and 4.0 , indicating satisfactory performance. The results indicate that Australian clients take relationship enhancement seriously and the use of idea harnessing is at a high level.

\subsubsection{Variable-level performance}

Variables related to all client-led enablers and project's innovative performance were further analyzed in addition to the scale level analysis. When looking at these individual variables, the results show that there are no variables with the mean value of less than 2 , indicating that there were no extremely unsatisfactory performers. However, the following variables (see Table 5) had mean values between 2 and 3, indicating relatively low performance. 
Variables under Group $\mathrm{C}$ belong to incentivisation, covering strategies such as personal and financial incentives, provision for contractors to receive monetary benefits from innovative activities. It could be seen that most of the Group $\mathrm{C}$ variables are low performing, indicating that providing incentives for promoting innovation is not practiced much in the Australian construction industry.

However, the low mean values for variables belonging to the Group E variables appear to be justifiable. This group relates to the recognition of innovative projects. Only a few projects, which are far superior in performance as compared to others, belong to this group.

Therefore, the low mean values can be expected indicating the number of projects deserving high recognition is low.

On the other hand, the mean values of the following variables in Table 6 scored higher when compared to other variables considering that 3 being the median value representing the neutral position.

\section{[Insert Table 6 here]}

These results show that out of the 14 variables given in Table 6 , most belong to Group D (7 variables), which is on project team fitness. It also could be seen that out of these seven variables, five belong to $\mathrm{D} 3$, which is project team environment. Therefore, it can be concluded that Australian project teams (client's) are generally high performing with conducive team environments. In addition, the results show that:

- The experience and technical competence of Australian project managers are generally high

- Client's teams tend to have good relationships with key stakeholders

- They tend to seek input from experienced personnel extensively

- Australian construction projects tend to achieve better outcomes such as achieving operational goals.

Following analysis of the performance of variables related to different categories, attention was focused on assessing the innovativeness of client organizations.

\subsubsection{Innovativeness of Australian construction client organizations}

As shown by many researchers, the task of promoting innovation in projects is easy if the client organization, itself, is innovative. Research by Dulaimi et al. (2005) showed that construction organizations could foster innovation on projects by creating proper organizational climate. Tatum (1989) stated "the firms producing construction innovations appeared to contain several common elements of an innovation culture. This included persistent pursuit of improved productivity, the arrogance to question everything and all team members, and a pride in winning competition to find ways to improve". Panuwatwanich et al. (2008) also emphasized the importance of construction organizations being innovative to successfully manage and diffuse innovation. Therefore, it was interesting to know how the participants of this survey perceived the innovativeness of client organizations.

The survey provided valuable insight into participant's perception of client organizations on their innovativeness and supportiveness. Question 2D5.3 requested participants to rank whether they believed that the client organization had characteristics of an innovative organization.

The innovative organizational characteristics referred to above were: 
- Trusting employees and providing them with a degree of freedom of thought and action with no blame culture, especially with regard to mistakes done in the process of innovation.

- Providing recognition, encouragement, support and robust incentives towards innovative activities.

- Providing opportunities for networking facilities within and outside the organization.

- Top management showing its commitment to promoting innovation through their actions.

- Having a separate unit dedicated to promoting innovation in the organization and a strong focus on knowledge management.

- Allocating funds for research and development.

- Organization having processes to recognize and reward innovators.

- Organization having management systems to capture good ideas and monitor the progress of their implementation.

- Employees encouraged to have strong relationships with customers and other stakeholders.

Considering the fact that 3 being the median value representing the neutral position, the mean value for this question was 3.34, which was satisfactory, but not high. Another variable, "2D5.1: The client organization supported innovative activities of the project" had a mean value of 3.63, which was also not high. The results suggest that Australian construction organizations need to make a concerted effort to promote innovative culture within their organizations.

In addition to the above analyses, the research provided the opportunity to make the following comparisons: public and private sector organizations; different delivery types; and different cost types. First, the comparison between public and private sector organizations is discussed.

\subsubsection{Comparison between public and private sector organizations}

There has been much discussion in recent years on the innovative performance of public sector organizations as compared to private sector organizations. Citing the fact that the public sector globally characterized as conservative, bureaucratic and reluctant to change, many researchers argue that the public sector is not as innovative as it should be. On the other hand, this position has been questioned by others arguing it is a view that is either unsubstantiated or simply incorrect (Kay and Goldspink, 2016). Therefore, it is interesting to find out how public and private sector organizations belonging to the construction industry perform with respect to innovation.

The number of cases considered in the analysis included 75 public sector organizations and 40 private sector organizations. An analysis was performed to compare the means of variables belonging to above two sectors of organizations.

First, the variables belonging to each of the five independent categories representing four client-led enablers (i.e. idea harnessing, relationship enhancement, incentivisation, project team fitness) and innovative performance were averaged, and mean values were tested to find out whether there was a statistical difference between their mean values between public sector and private sector groups. As the data to be examined was in Likert scale the MannWhitney $U$ test was used. This test measures asymptotic significance (2-tailed) $p$-value. None of the categories had $p$-values $\leq 0.05$, therefore not rejecting the null hypothesis that the mean values are same for both public and private sector groups tested at $95 \%$ 
confidence interval. It can thus be concluded that there is no statistical evidence that the mean values between public sector and private sector groups are different.

In addition, a statistical analysis was carried out on individual variables using the MannWhitney $U$ test. The results show that 7 variables (out of 62 variables) have $p$-values $\leq 0.05$ rejecting the null hypothesis that the mean values are same for both public and private sector groups tested at $95 \%$ confidence interval. This means that the mean values between public sector and private sector groups of these variables are different. These results are discussed below, with possible explanations.

According to the results, the client's project teams of the public sector group respect other teams more than the private sector group and the public sector project teams are having better relationships with other parties as compared to the private sector. Possible reasons for this could be that most public sector organizations have a bargaining power due to the possibility of awarding repetitive work. The service providers, therefore, may take extreme care to maintain good relationship with public sector clients. Such constraints may not exist, in general, for private sector contracts, which are generally 'one-off', and the service providers could go for maximizing their profit margins in such cases, which may not favorably impact on relationships. As respecting each other teams is a two-way process, it could be that the client's teams reciprocating the goodwill to maintaining good relationships.

It is also shown that the public sector organizations selected contract types such as alliances more than the private sector. A possible reason for this could be that the public sector clients are more concerned about avoiding failures due to public perception and collaborative contract types such as alliances have a high probability of avoiding project failures. On the other hand, the private sector could be more concerned about the cost of such contracts, which some consider high.

With regard to project team members having exposure to innovation, public sector performed better, probably due to the repetitive nature of public sector contracts the client's team members are more experienced and would have had exposure to innovation in previous projects.

With regard to achieving the project outcome of satisfied customers, public sector performed better. A possible explanation could be that the public sector organizations are very sensitive to the opinions of the public and take extra precautions and spend more money to satisfy the public. The amount spent for the project for this purpose is generally not a major concern. On the other hand, the private sector would spend the minimum expenditure, which may not guarantee satisfied customers.

Private organizations performed better in achieving the project outcome of sustainable outcomes and reduced waste. The reduced waste may be linked to the private sector organization's effort to reduce unnecessary expenditure.

With the question "we used improved computer software/ hardware, models and communication systems", the private sector organizations performed better. This result is in agreement with the statement that Australian private sector organizations are more innovative in the area of construction management as compared to the public sector.

Researchers have provided possible explanations for this low performance by public sector organizations, some of which are given below:

- In business, organizations need to innovate - or die. In the public sector it is unlikely that organizations will collapse due to lack of innovation (Mulgan and Albury, 2003). 
- The obligation to maintain continuity, the need to provide acceptable standards in key services and accountability to tax payers through Parliament and local authorities can induce a culture of risk aversion which impedes or blocks innovation (Mulgan and Albury, 2003).

- Innovation is not an elemental context for the public sector. Failure to innovate rarely has devastating consequences; it is effectively just more work and the first thing jettisoned when time or budget pressures mount (Pott and Kastelle, 2010).

- Failure is particularly expensive in the public sector due to competitive media and opposition monitoring. The avoidance of failure is thus an organizational priority (Pott and Kastelle, 2010). For innovation to occur, risk taking is often required.

\subsubsection{Comparison between project delivery types}

The survey collected information on the delivery type of projects including the following: (a) Design, Bid and Build (the design is done by one party and the construction is carried out by another party after completing the design); (b) Design and Build (the design and construction by one party); and (c) collaborative contracts (the delivery using collaborative contracts such as alliance and Early Contractor Involvement Contract). To avoid confusion, it should be noted that the project delivery types mentioned here and the forms of relationships mentioned in Table 3 are two different aspects considered in the research.

Design and Build delivery type was the most reported in the survey $(50 \%)$, followed by Design, Bid and Build (34\%). Alliance or other collaborative contracts (13\%) constituted the other type. There were only four Early Contractor Involvement contracts (3\%). For comparison purposes, Early Contractor Involvement type were added to Alliance or other collaborative contracts naming them as Collaborative Contracts.

Statistical analysis was undertaken to study delivery types using the following procedure. The variables belonging to each of the five independent categories representing four clientled enablers (i.e. idea harnessing, relationship enhancement, incentivisation, project team fitness) and innovative performance were averaged and tested to find out whether there is a statistical difference between their mean (or median) values between different delivery type groups. As the data to be examined was in Likert scale and therefore discrete, the Kruskal Wallis test was used. It was not possible to use the Mann-Whitney $U$ test, which was only to test groups of two. This test is a non-parametric test. However, this test only compares the medians.

The test results showed that none of the groups had asymptotic significance $p$-values $\leq 0.05$, therefore not rejecting the null hypothesis that the median values are same for three delivery types tested at $95 \%$ confidence interval. This means that there was no statistical evidence to confirm that the mean values between groups were different.

After this, a further statistical analysis was carried out on individual variables using the same Kruskal Wallis test. The results showed that 5 variables (out of 62 variables) had $p$-values $\leq$ 0.05 rejecting the null hypothesis that the median values are same for different delivery types tested at $95 \%$ confidence interval. This shows that their mean values were different from each group. The results show that the client's project team of the design, bid and build delivery type scored much above others, possibly because the responsibility of the client's team is high for taking independent decisions. In other cases, the client's team may get advice from the contracting and other teams.

It can be seen that the client team felt more support from its parent organization in a collaborative delivery type. Collaborative delivery type needs more input from the client and 
those organizations capable of providing such support generally undertake this delivery type, which may be the explanation.

A collaborative delivery type requires flexibility from the client, which could involve relaxation of technical regulations/ specifications and this could be the explanation for receiving a higher value for the question "client organization's relaxation of technical regulations/ specifications supported innovative activities". While interpreting these results, it needs to be noted that the survey looked at construction projects from the perspective of a project team member working for the client (or owner) of the project. The member may be from a team representing the owner such as the consultant, design, superintendent team.

Some of the above findings are supported by several researchers. For example, Rahman et al. (2012) have identified Early Contractor Involvement contracts as an innovative form of contracts. They also have highlighted the importance of contractor's expertise, experience and understanding of the construction process and the consideration of buildability issues earlier in the design process. Meanwhile, Davis and Love (2011) have identified Alliance as a form of innovative contracts and underlined the importance of collaboration and improved relationship in enhancing innovative outcomes.

\subsubsection{Project cost comparison}

As per the survey, the following numbers of projects fell under different cost groups:

- Less than $\$ 100,000$ (8 projects);

- 100,000 to $\$ 1$ Million (19 projects);

- Over $\$ 1$ Million to $\$ 100$ Million (64 projects);

- Over \$100 Million to \$200 Million (8 projects); and

- Over $\$ 200$ Million (16 projects).

In order to simplify the analysis, the following groups were considered with the corresponding number of projects: Less than $\$ 1$ Million: 27 ; Over $\$ 1$ Million to $\$ 100$ Million: 64; Over \$100 Million: 24.

Similar to the delivery type analysis, the variables belonging to each of the five independent categories were averaged and tested to find out whether there is a statistical difference between their mean (or median) values between different cost groups using the Kruskal Wallis test. It was revealed that idea harnessing and innovative performance had $p$-values $\leq$ 0.05 rejecting the null hypothesis that the median values are same for different cost groups tested at $95 \%$ confidence interval. This shows that their mean values were different from each group. Table 7 shows mean values for each group, which were used for comparing purposes.

\section{[Insert Table 7 here]}

It could be observed from the results shown in Table 7, as the project is costing more, the performance under each category gets better, indicating that the clients have provided in more efforts to improve the performance. Most remarkable improvement is seen in idea harnessing.

Similar to the delivery types, the individual variables were further analyzed using the Kruskal Wallis test. The results show that 11 variables had $p$-values $\leq 0.05$ rejecting the null hypothesis that the population medians are equal for different delivery types tested at $95 \%$ confidence interval. They are given in Table 8. 
Similar to the results shown in Table 7, as the project cost increases, generally the performance for the mean scores increase improve, indicating that the clients have provided in more efforts to improve the performance. However, cases in 2A2.4, 2D2.3, 2D4.3 and 2E1.1 there is a small difference between different delivery types.

These results are in agreement with the findings of Tawiah and Russel (2008), who reported that the relative ability to drive project innovation increases with the increased cost of the project.

\section{Conclusion}

This paper has discussed a research on analyzing enablers, made possible through client actions, which promote innovation during the execution of construction projects. Data relating to a number of factors, identified through an extensive literature review, were collected through a survey of industry practitioners and analyzed using statistical techniques. These factors were categorized under the independent scales: idea harnessing, relationship enhancement, incentivisation, and project team fitness.

The results reported in this paper, which are based on the perceptions of project personnel engaged in construction projects who participated in the survey, paints a picture of how the Australian construction industry is performing with respect to innovation at the project level.

The innovative performance of construction projects in Australia appears to be above average, although the perceived level is not too high. One of the factors appear to contribute to somewhat higher innovative performance of Australian construction projects is that Australian project teams (clients) are generally high performing teams achieving strong project outcomes with high levels of team environment and team culture. On the other hand, it appears that the lesser consideration given in providing rewards/ incentives to promote innovative outcomes of projects remains a barrier to achieving higher innovative performance.

Much discussion has taken place among the research community whether the public sector organizations innovative or not as compared to private sector organizations. The results here show that the projects belonging to public sector organizations in Australia in the construction industry perform poorly as compared to those in private sector organizations, when it comes to innovation. However, results also show that the public sector is ahead in areas such as respecting other teams and having better relationship with stakeholders.

When comparing different delivery types, it is apparent that collaborative contracts perform better in the area of innovation, followed by design, bid and build delivery type. The performance of design and build delivery type appears to be least performing out of the three delivery types.

As the cost of projects increase, generally the innovative performance gets better, indicating that the clients have provided in more efforts to improve the performance.

Overall, the research reported in this paper provides a mixed picture about the innovative performance of Australian construction projects. The main finding of the research is that Australian clients could achieve higher outcomes from construction projects by promoting innovativeness in their projects, especially by promoting innovativeness in their own organizations and providing incentives/ rewards and other support for innovative activities in projects. The research identified a number of enablers for clients to use to achieve greater benefits from their projects through innovation. To further enhance and extend on the 
present research, future work could consider analyzing different forms construction innovations, and their applicability, that are independent to projects.

\section{References}

Asad, S., Fuller, P., Pan, W., and Dainty, A. R. J. (2005), "Learning to innovate in construction: a case study", paper presented at the ARCOM Conference, 7-9 September 2005, London, UK.

Berenson, M. L., Levine, D. M., \& Krehbiel, T. C. (2006), Basic Business Statistics: Concepts and Applications, 10th Edition, Pearson Education Australia, NSW, Australia.

Bhattacherjee, A. (2012), Social Science Research: principles, methods, and practices, Book 3., USF Tampa Bay Open Access Textbooks Collection.

Blayse, A. M., \& Manley, K. (2003), "Influences on construction innovation: a brief overview of recent literature", Report 2001-012-A-04 Literature Review, Cooperative Research Centre for Construction Innovation, Queensland University of Technology, Brisbane, Australia.

Briscoe, G. H., Dainty, A. R., Millett, S. J. and Neale, R. H. (2004), "Client-led strategies for construction supply chain improvement", Construction Management and Economics, Vol. 22 No.2, pp.193-201.

Brockmann, C., Brezinski, H., \& Erbe, A. (2016), "Innovation in Construction Megaprojects", Journal of Construction Engineering and Management, Vol. 142, No. 11, pp. 04016059 1-9.

Bygballe, L. E., \& Ingemansson, M. (2014), "The logic of innovation in construction", Industrial Marketing Management, Vol. 12, pp. 512-524.

Chen, H. L. (2014), "Innovation stimulants, innovation capacity, and the performance of capital projects", Journal of Business Economics and Management, Vol. 15 No. 2, pp .212231.

Cheng, M.I., Dainty, A. R. J., and Moore, D. R. (2005), "What makes a good project manager?”, Human Resource Management Journal, Vol. 15 No. 1, pp, 25-37.

Cheung, Y. K. F., and Rowlinson, S. (2011), "Supply chain sustainability: a relationship management approach", International Journal of Managing Projects in Business, Vol. 4 No. 3, pp. 480-497.

Cheung, Y. K. F., Rowlinson, S., \& Jefferies, M. (2005), "A critical review of the organizational structure, culture and commitment in the Australian construction industry", paper presented at the International Symposium of CIB W92/TG23/W107 on the Impact of Cultural Differences and Systems on Construction Performance, Las Vegas, Nevada.

Davis, P., and Love, P. (2011), "Alliance contracting: adding value through relationship development", Engineering, Construction and Architectural Management, Vol. 18 No. 5, pp. 444-461.

Dulaimi, M. F., Ling, F. Y. Y., and Bajracharya, A. (2003), "Organizational motivation and inter-organizational interaction in construction innovation in Singapore", Construction Management and Economics, Vol 21 No. 3, pp. 307-318.

Dulaimi, M. F., Ling, F. Y. Y., Ofori, G., and De Silva, N. (2002 b), "Enhancing integration and innovation in construction", Building research \& information, Vol. 30 No. 4, pp. 237-247. 
Dulaimi, M. F., Nepal, M. P., and Park, M. (2005), "A hierarchical structural model of assessing innovation and project performance", Construction Management and Economics, Vol.23 No. 6, pp. 565-577.

Gambatese, J. A., and Hallowell, M. (2011), "Factors that influence the development and diffusion of technical innovations in the construction industry", Construction Management and Economics, Vol 29 No. 5, pp. 507-517.

Gans, J., \& Stern, S. (2003), "Assessing Australia's innovative capacity in the 21st century", Intellectual Property Research Institute of Australia, University of Melbourne, Victoria, Australia, available at:

http://melbourneinstitute.unimelb.edu.au/outlook/assets/2003/JoshuaGans.pdf (accessed 19 April 2018).

Hughes, R. \& Thorpe, D. (2014), "A review of enabling factors in construction industry productivity in an Australian environment", Construction Innovation, vol. 14 no. 2, pp. 210228.

Ibrahim, C. K. I. C., Costello, S. B., Wilkinson, S., \& Walker, D. (2017), "Innovation in alliancing for improved delivery of road infrastructure projects", International Journal of Managing Projects in Business, Vol. 10 No. 4, pp. 700-720.

Kay, R., \& Goldspink, C. (2016), "Public Sector innovation: Why it's different", The Australian Institute of Company Directors, Australia available at: https://aicd.companydirectors.com.au/ /media/cd2/resources/advocacy/governanceleadership-centre/pdf/05493-1-pol-glc-public-sector-innovation-research-paper-a4may16_web.ashx (accessed 19 April 2018).

Khalfan, M. M. A., \& McDermott, P. (2006), "Innovating for supply chain integration within construction”, Construction Innovation: Information, Process, Management, Vol 6 No. 3, pp. 143-157.

Kulatunga, K., Kulatunga, U., Amaratunga, D., \& Haigh, R. (2011), "Client's championing characteristics that promote construction innovation", Construction Innovation: Information, Process, Management, Vol. 11 No. 4, pp. 380-398.

Ling, F. Y. Y. (2003), "Managing the implementation of construction innovations", Construction Management and Economics, Vol. 21 No. 6, pp. 635-649.

Love, P. E. D., Davis, P. R., Chevis, R., \& Edwards, D. J. (2010), "Risk/reward compensation model for civil engineering infrastructure alliance projects", Journal of Construction Engineering and Management, Vol. 137 No. 2, pp. 127-136.

Lu, S. L., \& Sexton, M. (2006), "Innovation in small construction knowledge-intensive professional service firms: a case study of an architectural practice", Construction Management and Economics, Vol. 24 No. 12, pp. 1269-1282.

Manley, K. (2006), "The innovation competence of repeat public sector clients in the Australian construction industry", Construction Management and Economics, Vol. 24 No. 12, pp. 1295-1304.

Manley, K. (2008), "Implementation of innovation by manufacturers subcontracting to construction projects", Engineering, Construction and Architectural Management, Vol. 15 No. 3, pp. 230-245. 
Manley, K., \& Mcfallan, S. (2006), "Exploring the drivers of firm-level innovation in the construction industry", Construction Management and Economics, Vol. 24 No. 9, pp. 911920.

Mulgan, G., \& Albury, D. (2003), "Innovation in the Public Sector", UK Cabinet Office, Admiralty Arch, The Mall, London SW1A 2WH, UK.

Murphy, M., Heaney, G., \& Perera, S. (2011), "A methodology for evaluating construction innovation constraints through project stakeholder competencies and FMEA", Construction Innovation: Information, Process, Management, Vol. 11 No. 4, pp. 416-440.

Nam, C., \& Tatum, C. (1997), "Leaders and champions for construction innovation", Construction Management \& Economics, Vol. 15 No. 3, pp. 259-270.

Núñez, J. L. (2011), Social Idea Generation, Final Paper, Berkeley University of California, available at: http://people.ischool.berkeley.edu/ limon/papers/Final\%20Paper\%20\%20Social\%20Idea\%20Generation.pdf (accessed 20 February 2012).

Ozorhon, B. (2012), "Analysis of construction innovation process at project level", Journal of Management in Engineering, Vol. 29 No. 4, pp. 455-463.

Ozorhon, B. (2013), "Analysis of Construction Innovation Process at Project Level”, Journal of Construction Engineering and Management, Vol. 29 No.4, pp. 455-463.

Ozorhon, B., Oral, K., \& Demirkesen, S. (2016), "Investigating the Components of Innovation in Construction Projects", Journal of Construction Engineering and Management, Vol. 32 No. 3, pp. $040150521-10$.

Ozorhon, B., \& Oral, K. (2017), "Drivers of Innovation in Construction Projects", Journal of Construction Engineering and Management, Vol. 143, No. 4, pp. 04016118 1- 9.

Panuwatwanich, K. (2008), "Modelling the Innovation Diffusion Process in Australian Architectural and Engineering Design Organizations, PhD Thesis, Griffith University, Gold Coast, Australia.

Panuwatwanich, K., Stewart, R. A., \& Mohamed, S. (2008), "The role of climate for innovation in enhancing business performance: the case of design firms", Engineering, Construction and Architectural Management, Vol. 15 No. 5, pp. 407-422.

Pott, J., \& Kastelle, T. (2010), “Public sector innovation research: What's next?", Innovation: management, policy \& practice, Vol. 12 Issue 2, pp. 122-137.

Price, C., \& Davis, M. (2002), Fueling Innovation: Igniting the Entrepreneurial Spirit, VentureQuest Ltd, Denver, Colorado, USA.

Rahman, M., \& Alhassan, A. (2012), "A contractor's perception on Early Contractor Involvement", Built Environment Project and Asset Management, Vol. 2 No. 2, pp. 1-13.

Schieg, M. (2007), "Post-mortem analysis on the analysis and evaluation of risks in construction project management", Journal of Business Economics and Management, Vol. III No. 2, pp. 145-153.

Shalley, C. E., Zhou, J., \& Oldham, G. R. (2004), "The effects of personal and contextual characteristics on creativity: Where should we go from here?", Journal of management, Vol. 30 No. 6, pp. 933-958. 
Sills, S.J. \& Song, C. (2002), "Innovations in Survey Research: An Application of Web-Based Surveys", Social Science Computer Review, vol. 20, no. 22, pp. 22-30.

Stine, R., \& Foster, D. (2011), Statistics for business, Addison-Wesley, Pearson Education Inc., Boston, USA.

Tatum, C. B. (1989), "Organizing to increase innovation in construction firms", Journal of Construction Engineering and Management, Vol. 115 No. 4, pp. 602-617.

Tawiah, P. A., \& Russel, A. D. (2008), "Assessing infrastructure project innovation potential as a function of procurement mode", Journal of Management in Engineering, Vol. 24, pp. 173-186. 